\title{
We the People
}

\author{
Marvin L. Birnbaum, MD, PhD
}

The secret of caring for the patient is caring for the patient.

William Osler

The problem to be addressed ... is as simple as an abstract attitude, but is the day-to-day realities of the practice of medicine. Associated with this simple question are all the emotional stresses and difficulties of being a physician. Is it possible, in the contempory mileu, for the practice of medicine, conceived as the art of helping

the suffering, to be intrinsically rewarding, apart from the material gain and social recognition?

Jacob Needleman in The Way of the Physician, 1985
The 8th World Congress on Emergency and Disaster Medicine (WAEDM) is history-it has run its course-it has done its thing-it was a smashing success.

There are many measures of the success of the Congress. It provided a forum for presentation of the research and ideas of people from more than 40 countries who are concerned with the practice of Disaster and Emergency Medicine. It provided the forum for the presentation and discussion of more than 250 scientific works. The Abstracts for each of these presentations appear in this issue of Prehospital and Disaster Medicine. Some of these papers described wonderfully conceived and executed randomized, controlled, experimental studies. Some presentations provided insights into Disaster Medicine that only qualitative research efforts can elicit. Some, although weak in the traditional definitions of science, constituted the first foray of many budding young researchers into the scientific community. Each was greeted with enthusiasm and was provided with constructive comments. There were no attacks. There was much support.

The venue and forum provided by our Swedish hosts was superb and fostered communications at all levels. It was a coming together with a common idealthe enhancement of the ability of medicine to respond to societies in distress. It promoted the expression of the concern of a relatively small segment of the population of earth to share sensitivities to the condition of other human beings and express and give evidence of an unstinting willingness to give of themselves to minimize the sufferings of others. The people came together to share and to replenish the energy required to sustain such a noble ideal. Each brought different experiences in the context of their special culture and presented distinct views associated with different expectations. Yet, the ultimate goals were identical. The forum gave all of us a unique chance to share and learn-and share and learn we did. It was exciting. It was stimulating. It was happy and parts were sad. It was marked by a drive to gain understanding. It was remarkable experience. It was energizing.

The forum provided the much needed opportunity for WAEDM to reexamine its mission and promoted its reorganization in response to a need by the world community concerned with the prevention, mitigation, and response to disasters. It refashioned itself into the structure necessary to provide the cornerstone for the worldwide cooperation necessary to assist all organizations for Disaster and Emergency Medicine in the world. It even examined its name and revised it: it now is incorporated as the World Association for Disaster and Emergency Medicine (WADEM). Indeed, it is a new beginning with an expanded mission and with renewed energy. And the world grew smaller and the people came closer together.

But most of all, it was the people who attended this Congress. The nature of the persons who have commitment to the practice of Disaster Medicine was most striking; these are extraordinary and astounding people who give profoundly of themselves for no external rewards. In this new discipline, there are no monetary rewards or needs for advancement. There is no competition. The persons who came to Stockholm to share and to grow are a valuable breed. They fight an uphill battle to achieve what they know is necessary; seeking access to many of the same resources demanded by others who need them to achieve their respective missions. With but a few exceptions, the world is poorly prepared for disaster, and it is an ongoing chore to wrestle for resources necessary for preparedness. Those involved with Disaster Medicine plan and struggle to be prepared for what could happen. Each of these persons 
is sensitive to the human condition. Each believes in the potential of humanity. Each believes in peace. They learned that when others share their dreams, they need not go this difficult road alone. Most of the problems encountered are common to all. There are many who are willing to help. These people help define humanitarianism.

Perhaps, the most apparent evidence of the level of caring and sensitivity of these participants was their response to the unscheduled presentation of a remarkable video tape. The tape was produced by Leonid Roshal from the Russian Republic. It documented the reactions of children to the disasters of war and interhuman conflict. Dr. Roshal had finished the production of this tape just prior to the Congress and brought it with him to gather feedback from a few individuals. He planned to show it only once, but it had to be shown again and again. The reaction of all who experienced it was characteristic: it presented a startling picture of the impact of disasters and for this audience, it was a poignant reminder of why they are so committed to the practice of Disaster Medicine. Tears came to the eyes of all the beholders; it served to renew their commitment to lessen the suffering of the children victims of disaster. It served as a magnet for these people, because it reaffirmed their purpose and their common goal.

The people who make Disaster Medicine a major part of their life are wonderful human beings. Their selfishness is confined only to how they can make life a little better for others. They embody the real reason I attended medical school. Their motivation is the basis of what has made medicine so great. They embody the ideals upon which all the good of medicine is based. They renew one's faith in humankind.

It is refreshing to come to know such persons. It is energizing. It is a privilege to walk among them. People that reach out beyond their immediate surroundings and devote their lives, skills, and expertise to heal the wounds brought by disaster and war deserve our support and applause. Those that attended the Congress in Stockholm are people of that caliber. 